Journal of Money and Economy

Vol. 15, No. 1, Winter 2020

pp. $55-74$

DOI: $10.29252 /$ jme.15.1.55

Original Research Article

\title{
The Effect of Central Bank's Monetary Policy on Unemployment and Inflation in Provinces of Iran: A GVAR Approach
}

\author{
Nasrin Ebrahimi* \\ Mehdi Pedram ${ }^{\dagger}$ \\ Mir Hossein Mousavi ${ }^{*}$
}

Received: 4 Feb 2020

Approved: 7 Apr 2020

The national economy of most countries is made up of various regions (provinces) with different industrial composition, financial structure, trade relations, and institutional environment. Depending on these characteristics, regions may respond differently to a uniform national macroeconomic policy. Policymakers should consider these heterogeneities to achieve the national development objective. Using separate VAR models to investigate the regional effects of a uniform policy neglects the spillover effects across regions. The GVAR approach models the links between units (such as regions) using the weighted average of different macroeconomic aggregates. Since Iran is a regionally dispersed country, this motivates us to analyze whether or not a standard monetary policy has different effects on its provinces' unemployment and inflation rates using a GVAR approach during 2005q1-2016q1 period. Results indicate that one standard deviation positive monetary shock at the national level can significantly reduce unemployment in some provinces. These responses are similar in terms of timing, but their intensity is different. Also, this positive shock has a positive effect on inflation in all provinces. All responses are approximately similar in terms of timing. Despite this similarity, shock responses vary in terms of intensity.

Keywords: Monetary Policy, Provincial Effects, GVAR Approach.

JEL Classification: C13, E52, R11.

\section{Introduction}

Macroeconomic analyzes and policy assessments require taking into account interdependencies existing across sectors, markets, and regions. Monetary

\footnotetext{
* Faculty of Social Sciences and Economics, Alzahra University, Tehran, Iran; nasrin.ebrahimmi@gmail.com (Corresponding Author)

$\dagger$ Faculty of Social Sciences and Economics, Alzahra University, Tehran, Iran; mehdipedram@alzahra.ac.ir.

$\$$ Faculty of Social Sciences and Economics, Alzahra University, Tehran, Iran; hmousavi@alzahra.ac.ir.
} 
policy as a macro policy is structurally designed to achieve national targets, including price stability; the national economy is made up of various areas with different structures and characteristics. Therefore, the impacts of the same monetary policy can affect regions differently within a single economic entity depending on regional industrial composition, financial structure, trade relations, and institutional environment (Ridhwan et al., 2014). Also, possibly the macroeconomic policies in one region caused economic effects on another region. Such effects are called spillover effects. Therefore, policymakers need to consider a number of different channels of transmission and spillover effects.

From the literature, industry mix, firm size, and bank size have emerged as three of the reasons which may account for differential regional effects of uniform monetary policy. These reasons have different theoretical underpinnings, for example, firm size and bank size serves as an empirical measure for the credit channel and industry mix is usually associated with the interest rate channel (Arnold \& Vrugt, 2004).

Considering the different impact of economic policies on the regions in a country has become a subject of recent interest in the economic literature. Accordingly, Carlino and DeFina (1998) indicated that there is little doubt about the effect of the central bank's monetary policy on an aggregate entity. But analyzing from the perspective of regional and state economies, monetary policy has different effects depending on the economic diversity, demographics, financial development, and other factors. As a consequence, the real economic impacts of uniform monetary policy need not be homogeneous across regions. It is true, especially for a developing country with a vast geography and different social and economic conditions.

There are substantial studies that assess the impact of monetary policies on the regional economic dynamics of different countries. Most of these studies (such as Carlino \& DeFina, 1998; Arnold \& Vrugt, 2002; Owyang et al., 2009; Ridhwan et al., 2014; Beckworth, 2015) undertake their purposes using impulse response functions (IRFs) from the estimated VAR model. Investigating a large number of regions and fitting a single VAR model to large time-series data is not feasible due to a decrease in degrees of freedom, so the authors estimated a separate VAR model for each region. While, as noted by Carlino and DeFina (1998), when modeling regional responses to aggregate shocks, it is essential to consider spillover effects among regions. Therefore, the simple estimation of VAR for each region would neglect these effects. To overcome these difficulties, the Global Vector Auto-Regressive (GVAR) model has advantages. The GVAR approach is modeling the links 
between units (such as regions) using the weighted average of different macroeconomic aggregates. This approach can draw the dynamics of the transmission of the shocks of both national and regional variables and provide more information than the traditional VAR model.

Some studies (Foroughifar, 2016) investigated provincial responses to monetary policy in Iran using VAR models. But there is no study analyzing these responses in global macro-econometric models. The aim of this paper, for the first time, is analyzing whether monetary policy has a different impact on unemployment and inflation in different provinces. Therefore, the framework of the GVAR model is used based on impulse response functions and variance decomposition. We use quarterly data from 2005q1 to 2016q1 to estimate the model, including 30 provinces in Iran.

The rest of the paper is organized as follows. We study the literature on the regional effects of monetary policy in section II. Then, section III explains the methodology of the study - empirical results described in section IV. Finally, we conclude in section $\mathrm{V}$.

\section{Literature Review}

The monetary transmission mechanism can be defined as the process through which monetary policy decisions are transmitted into changes in economic growth and inflation (Taylor, 1995). It is based on several channels and describes how policy-induced changes in nominal money stock or short-term nominal interest rate and affect real variables such as aggregate output and employment (Ireland, 2006). Transmission mechanism channels include interest rate, exchange rate, other asset prices, and the so-called credit channel effects (Mishkin, 1995). The operation of these channels in different countries, sectors, and regions depends on their characteristics. The cross-country asymmetries in the effectiveness of monetary transmission can be replicated by accounting for differences in countries' financial structure, labor market rigidities, and manufacture mix (Georgiadis, 2014; Mishra et al., 2016). Monetary policy will affect regional economies as well as national economies through monetary transmission channels. The literature on the monetary transmission mechanism shows some reasons why the authorities' policies have different regional effects, including the mix of industries, number of large versus small firms, and the number of large versus small banks. These reasons have different theoretical underpinnings. While firm and bank size serve as an empirical measure for the credit channel, industry mix is usually associated with the interest rate channel. 
Differential industry mix: At the national level, timing and impact of monetary policy vary across industries. These differences arise because of varying interest sensitivities in demand for products. It is agreed that the degree of sensitivity to interest rate shocks differs across industries. For example, manufacturing and construction are more credit-dependent than either agriculture or services; hence, relatively industrialized regions to be more affected by monetary policy than their less industrialized counterparts (see Ridhwan et al., 2010). So areas with a high proportion of interest-elastic industries may be especially vulnerable to a tightening of monetary policy. Monetary contractions may reduce the demand for investment goods and (durable) consumer goods by increasing the real costs of capital to firms and consumers (see Mishkin, 1995; Taylor, 1995). Similarly, the differences in an industry's response depend on whether its output is necessary or luxury, and the extent to which the demand for the industry's production is linked to foreign trade and the foreign economy's health. These different industry responses, together with varying mixes of the industry across states, provide a proper way for monetary policy to have different state effects (Carlino \& DeFina, 1998).

The different mix of firms: According to the credit channel theory, credit market imperfections, and financing constraints arising from information asymmetries, increase the monetary policy effects. As a consequence, the availability of credit for firms is dependent on the value of their assets. If rising interest rates tighten credit market conditions, this will affect the balance sheet positions of firms: higher interest payments reduce cash flow, and higher interest rates lower the market value of assets. A monetary policy tightening may leave firms with restricted access to credit. The firms which are more likely to be affected by this channel are small, so due to higher informational asymmetries, the amount of collateral they have to pledge is relatively higher. A balance sheet weakening due to a monetary policy tightening can imply that they might become credit-constrained (Ehrmann, 2005). Monetary policy effectiveness is, therefore, assumed to increase with the proportion of small firms in an economy (Raabe et al., 2006). Consequently, activity in a state that has a high concentration of small firms could be especially sensitive to the monetary policy.

The different mix of banks: Based on the lending view, one should expect that the loans and security portfolios of large and small banks show different sensitivity to a contraction in monetary policy. Romer and Romer (1990) emphasize that Bank financing can be done through non-deposit resources of funds. Thus, even if the contractionary monetary policy can reduce the 
banking sector's availability to deposit funds, some banks can simply make the shortage by issuing large-denomination certificates of deposit, mediumterm notes, or some other security. This kind of bank is insulated from monetary policy. Bank size explains the differences in financing abilities, with large banks having more funding options available than small banks. Thus, states, in which small banks make a disproportionately large share of bank loans, may respond more to monetary policy shifts than states that have a large share of loans made by the nation's large banks (Kashyap \& Stein, 1995).

\subsection{The Empirical Results}

There are significant studies that aimed to assess the monetary policy impact on the country's regions' economic dynamics. In general, these studies indicate that monetary policy has different effects in the regions depending on the region's industrial structure, productive capacities, technology, institutional features, financial development, and geographical location (Carlino \& DeFina, 1998, 1999; Nachane et al., 2002; Arnold \& Vrugt, 2002; Di Giacinto, 2003; Owyang et al., 2009; Ridhwan et al., 2014; Beckworth, 2015; Xiaohui \& Masron, 2014). Carlino and DeFina (1999) find evidence that the response of the U.S. states is positively correlated to the share of the manufacturing sector in state output. On the other hand, Di Giacinto (2003) finds evidence that interactions across states tend to smooth out responses across space. The results of Xiaohui and Masron (2014) provide evidence of different regional responses of real variables to monetary policy. Also, when examining the regional effects of monetary policy, the spillover effects among regions are significant in the short run. In the long term, the influence of deposits transfer among regions is much bigger than that of the spillover effects. Guo and Masron (2017) investigated the responses of Chinese provinces to monetary shocks in terms of magnitude and timing. This investigation also included the spillover effects among provinces. The results confirm that responses of provinces to monetary shocks are different. Still, the negative influence of deposit transfers, in the long run, is greater than the positive impact of the spillover effect. Some studies (e.g., Silva, 2016), show that regions tend to have similar responses in terms of monetary policy.

\subsection{Some Iranian Provinces Issues}

As shown in Table 1, the industry mix differs across provinces of Iran. For example, on average, about $22.8 \%$ of Isfahan province's GDP is allocated to manufacturing during 2005-2015, but this share is less than 2\% of GDP for 
Kohgiluyeh province. Services have a considerable role in GDP in most provinces of the country.

Table 1

Major industry average share of GDP in percent (2005-2015)

\begin{tabular}{|c|c|c|c|c|c|c|c|c|c|c|}
\hline Province & Agri. & $\begin{array}{l}\text { Oil } \\
\& \\
\text { Gas } \\
\end{array}$ & Min. & Mfg. & $\begin{array}{l}\text { Elec. } \\
\text { \& } \\
\text { Wat. }\end{array}$ & Cons. & Tran. & IT & Rel. & Serv. \\
\hline $\begin{array}{l}\text { Azerbaijan } \\
\text { East }\end{array}$ & 12.22 & 4.53 & 0.83 & 16.80 & 6.32 & 7.13 & 5.78 & 0.60 & 9.00 & 36.80 \\
\hline $\begin{array}{l}\text { Azerbaijan } \\
\text { West }\end{array}$ & 20.61 & 0.01 & 0.73 & 8.61 & 2.53 & 9.00 & 8.31 & 0.65 & 10.67 & 38.89 \\
\hline Ardabil & 27.21 & 0.02 & 0.16 & 6.76 & 2.16 & 7.68 & 4.86 & 0.55 & 7.53 & 43.08 \\
\hline Isfahan & 7.21 & 8.84 & 0.52 & 22.80 & 7.01 & 6.24 & 6.36 & 0.53 & 9.88 & 30.61 \\
\hline Ilam & 9.29 & 55.58 & 0.22 & 2.30 & 1.72 & 5.28 & 2.94 & 0.26 & 2.95 & 19.46 \\
\hline Bushehr & 4.85 & 28.43 & 0.17 & 20.35 & 22.33 & 3.28 & 4.44 & 0.24 & 2.94 & 12.96 \\
\hline Tehran & 2.00 & 1.33 & 0.06 & 11.17 & 2.42 & 6.31 & 8.15 & 4.08 & 18.95 & 45.52 \\
\hline Chaharmahal & 23.26 & 0.01 & 0.47 & 9.16 & 2.28 & 9.56 & 6.18 & 0.63 & 8.04 & 40.40 \\
\hline $\begin{array}{l}\text { South } \\
\text { Khorasan }\end{array}$ & 24.91 & 0.00 & 1.99 & 7.80 & 2.23 & 7.20 & 4.78 & 0.64 & 7.42 & 43.03 \\
\hline $\begin{array}{l}\text { Razavi } \\
\text { Khorasan }\end{array}$ & 12.97 & 0.23 & 0.39 & 10.45 & 5.12 & 7.41 & 6.98 & 0.53 & 13.48 & 42.44 \\
\hline $\begin{array}{l}\text { North } \\
\text { Khorasan }\end{array}$ & 20.93 & 0.00 & 0.69 & 12.38 & 4.72 & 8.46 & 5.76 & 0.44 & 6.93 & 39.68 \\
\hline Khuzestan & 4.69 & 61.27 & 0.07 & 9.05 & 3.73 & 2.09 & 4.02 & 0.15 & 2.85 & 12.08 \\
\hline Zanjan & 21.78 & 0.12 & 1.27 & 19.40 & 3.08 & 9.26 & 4.49 & 0.57 & 7.05 & 32.97 \\
\hline Semnan & 16.23 & 0.46 & 1.34 & 21.01 & 3.01 & 8.67 & 8.87 & 0.60 & 7.58 & 32.24 \\
\hline Sistan & 18.60 & 0.00 & 0.54 & 5.82 & 2.53 & 9.30 & 6.45 & 0.68 & 9.26 & 46.82 \\
\hline Fars & 18.65 & 3.87 & 0.70 & 9.57 & 7.90 & 7.13 & 6.32 & 0.61 & 12.38 & 32.86 \\
\hline Qazvin & 16.34 & 0.14 & 0.17 & 29.35 & 2.90 & 6.81 & 5.10 & 0.52 & 10.36 & 28.32 \\
\hline Qom & 7.90 & 0.35 & 0.37 & 16.36 & 3.17 & 10.34 & 5.52 & 0.77 & 14.50 & 40.73 \\
\hline Kurdistan & 19.00 & 0.01 & 0.80 & 5.76 & 3.24 & 8.07 & 4.47 & 0.69 & 8.83 & 49.13 \\
\hline Kerman & 25.31 & 0.57 & 10.55 & 14.85 & 3.44 & 5.36 & 4.58 & 0.46 & 6.99 & 27.89 \\
\hline Kermanshah & 14.72 & 1.47 & 0.30 & 9.86 & 6.85 & 7.27 & 5.09 & 0.55 & 12.93 & 40.97 \\
\hline Kohgiluyeh & 4.35 & 79.55 & 0.16 & 1.08 & 0.46 & 1.83 & 0.80 & 0.08 & 2.00 & 9.69 \\
\hline Golestan & 25.18 & 0.02 & 0.50 & 6.24 & 2.17 & 7.65 & 6.07 & 0.55 & 9.79 & 41.81 \\
\hline Gilan & 14.69 & 0.03 & 0.16 & 10.53 & 4.29 & 8.55 & 6.90 & 0.64 & 11.77 & 42.43 \\
\hline Lorestan & 21.34 & 0.58 & 0.79 & 7.33 & 1.59 & 7.19 & 5.31 & 0.57 & 11.90 & 43.40 \\
\hline Mazandaran & 24.47 & 0.00 & 0.24 & 10.15 & 3.43 & 5.44 & 7.80 & 0.69 & 9.59 & 38.17 \\
\hline Markazi & 11.56 & 8.96 & 1.19 & 24.33 & 5.51 & 5.04 & 3.79 & 0.40 & 5.86 & 33.37 \\
\hline Hormozgan & 10.58 & 13.21 & 0.39 & 6.04 & 7.87 & 5.74 & 23.68 & 0.43 & 6.21 & 25.84 \\
\hline Hamedan & 23.27 & 0.01 & 0.34 & 11.18 & 2.61 & 6.49 & 5.48 & 0.55 & 11.03 & 39.04 \\
\hline Yazd & 11.47 & 0.03 & 11.50 & 19.98 & 3.60 & 6.33 & 7.45 & 0.57 & 6.02 & 33.06 \\
\hline
\end{tabular}

Source: Statistical Center of Iran

\section{Methodology and Data}

The Global Vector Autoregressive (GVAR) approach provides a relatively simple, effective way for modeling interactions in a complex highdimensional system such as the global economy. The GVAR can be 
summarized as a two-step procedure. The first, small-scale country-specific models are estimated conditional on the rest of the world. These models are represented as augmented VAR models, denoted as VARX*. They feature domestic variables and weighted cross-section averages of external variables, which are also commonly referred to as 'star variables,' which are treated as weakly exogenous variables (or long-run forcing). In the second step, individual country VARX* models are stacked and solved simultaneously as one large global VAR model. The solution can be used for shock scenario analysis and forecasting, as is usually done with standard low-dimensional VAR models. The GVAR approach has been applied to a number of diverse problems. Individual units need not necessarily be countries but could be regions, industries, goods categories, banks, municipalities, or sectors of a given economy (Chudik \& Pesaran, 2016). This study assumes that the units are regions (provinces) of Iran.

\subsection{Modelling Interconnections Using GVAR}

Consider a panel of $\mathrm{N}$ cross-section units, each featuring $\mathrm{k}_{\mathrm{i}}$ variables observed during the periods $\mathrm{t}=1,2, \ldots \mathrm{T}$. Let $\mathrm{x}_{\mathrm{it}}$ denote $\mathrm{a} \mathrm{k}_{\mathrm{i}} \times 1$ vector of variables specific to cross-section unit $\mathrm{i}$ in time $\mathrm{t}$, and $x_{t}=\left(x_{1 t}^{\prime}, x_{2 t}^{\prime}, \ldots, x_{N t}^{\prime}\right)$ denote a $\mathrm{k} \times 1$ vector of all the variables in the panel, where $\mathrm{k}=\sum_{\mathrm{i}=1}^{\mathrm{N}} \mathrm{k}_{\mathrm{i}}$. At the core of the GVAR approach are small-scale unit-specific conditional models that can be estimated separately. These individual unit models explain the domestic variables of a given unit, xit, conditional on unit-specific crosssection averages of foreign variables, collected in the $\mathrm{k}^{\wedge *} \times 1$ vector

$x_{i t}^{*}=\widetilde{W}_{i}^{\prime} X_{t}$

Where $\mathrm{i}=1,2 \ldots \mathrm{N}$, and $\widetilde{W}_{i}$ is $k \times k^{*}$ matrix of unit-specific weights, typically constructed using data on bilateral foreign trade or capital flows.

$\mathrm{x}_{\mathrm{it}}$ is modeled as a VARX* model, namely a VAR model augmented by the vector of the 'star' variables $x_{i t}^{*}$, and their lagged values,

$X_{i t}=\sum_{\ell=1}^{p_{i}} \Phi_{i \ell} X_{i, t-\ell}+\Lambda_{i 0} X_{i t}{ }^{*}+\sum_{\ell=1}^{q_{i}} \Lambda_{i \ell} X^{*}{ }_{i, t-\ell}+\varepsilon_{i t}$

for $\mathrm{i}=1,2, \ldots, \mathrm{N}$, where $\Phi_{i \ell}$, for $\ell=1,2, \ldots, p_{i}, \Lambda_{i \ell}$, for $\ell=0,1,2, \ldots, q_{i}$, are $k_{i} \times k_{i}$ and $k_{i} \times k^{*}$ matrices of unknown parameters, respectively, and $\varepsilon_{i t}$ are $k_{i} \times 1$ error vectors. When estimating unknown coefficients of the conditional unit models, star variables can be considered as weakly exogenous. 
Consider $\mathrm{z}_{\mathrm{it}}=\left(\mathrm{X}_{\mathrm{tt}}, \mathrm{X}^{*}{ }_{1 \mathrm{t}}\right)$ as a vector with dimensions $\mathrm{k}_{\mathrm{i}}+\mathrm{k}^{*}$ that consist of domestic and unit-specific foreign variables included in the sub-model of unit i. Then, rewrite (2) as

$A_{i 0} z_{i t}=\sum_{\ell=1}^{p} A_{i \ell} z_{i t-\ell}+\varepsilon_{i t}$

Where

$A_{i 0}=\left(I_{k i}-\Lambda_{i 0}\right), A_{i \ell}=\left(\Phi_{i \ell}, \Lambda_{i \ell}\right)$, for $\ell=1,2, \ldots, p$

$p=\max \left(p_{i}, q_{i}\right), \Phi_{i}=0$, for $\ell>p_{i}$ and $\Lambda_{i}=0$, for $\ell>q_{i}$

The estimation of unit models in (2), which allows for cointegration within and across units (via the star variables), is the first step of the GVAR approach. The second step consists of stacking estimated unit models to form a large global VAR model.

Using the $\left(k_{i}+k^{*}\right) \times k$ dimensional 'link' matrices $W_{i}=\left(E_{i}, \widetilde{W}_{i}^{\prime}\right) \times r_{i}$, where $E_{\mathrm{i}}$ is selection matrix with dimensions $\mathrm{k} \times \mathrm{k}_{\mathrm{i}}$ that select $\mathrm{X}_{\mathrm{it}}=\mathrm{E}_{\mathrm{i}} \mathrm{X}_{\mathrm{t}}$. Also, $\widetilde{W}_{i}^{\prime}$ is the weight matrix introduced in (1) to define unit-specific foreign star variables. We have

$z_{i t}=\left(X_{l t}, X^{*}{ }_{t t}\right)=W_{i} X_{t}$

Using (4) in (3) yields

$A_{i 0} W_{i} X_{t}=\sum_{\ell=1}^{p} A_{i \ell} W_{i} X_{t-\ell}+\varepsilon_{i t}$

and stacking these models for $\mathrm{i}=1,2, \ldots, \mathrm{N}$, we obtain

$A_{i 0} W_{i} X_{t}=\sum_{\ell=1}^{p} A_{i \ell} W_{i} X_{t-\ell}+\varepsilon_{i t}$

Where $\varepsilon_{t}=\left(\varepsilon_{1 t}^{\prime}, \varepsilon_{2 t}^{\prime}, \ldots, \varepsilon_{N t}^{\prime}\right)$, and

$\mathrm{G}_{\ell}=\left(\begin{array}{c}A_{1 \ell} W_{1} \\ A_{2 \ell} W_{2} \\ \vdots \\ A_{N \ell} W_{N}\end{array}\right)$

If matrix $G_{0}$ is invertible, then by multiplying (6) by $G_{0}{ }^{-1}$ from the left, we obtain the solution to the GVAR model.

$X_{t}=\sum_{\ell=1}^{p} \mathrm{~F}_{\ell} X_{t-\ell}+\mathrm{G}_{0}^{-1} \varepsilon_{t}$

Where $\mathrm{F}_{\ell}=\mathrm{G}_{0}{ }^{-1} \mathrm{G}_{\ell}$ for $\ell=1,2, \ldots, p$. 


\subsection{Data}

Our objective is to evaluate the effects of monetary policy on Iran's provinces' economy. In this way, we use data for provinces. Our key variables are unemployment and inflation. We use the manufacturing share of GDP in each province as an indicator of a mix of industries. The choice of monetary policy indicator is essential to identify the monetary policy shocks. In Iran, with the monetary policy aimed at controlling monetary aggregates, attempts are made to prevent monetary expansion, incompatible with liquidity and inflation targets set in the development plans, and to finance productive and investment sectors. Therefore, we use M2 as an integrated monetary policy for all of the provinces. For this purpose, our quarterly data are collected from $2005 q 1$ to $2016 q 1$.

It must be reminded that the GVAR model introduces a regional linkage through a weight matrix that typically constructed using data on bilateral foreign trade or capital flows. Due to the lack of such data at the provincial level in Iran, provincial migration is used to make a weight matrix. The choice of provincial migration is due to its important role in explaining unemployment. The migration flow matrix has important characteristics of the weight matrix. For example, the elements on the main diagonal of the weight matrix are zero. It is possible to apply the migration matrix by removing intra provincial migration.

\section{Estimation of the GVAR Model}

To evaluate the effects of monetary policy on the provinces of Iran, we investigate the implication of a standard deviation positive shock to M2. Before implying this shock, some steps must be taken. These steps are explained below.

\subsection{Estimation of the Province-Specific Models}

Assume that external variables are exogenous. To test whether our time series include unit root or not, we used the HEGY seasonal unit root test. In the cases in which variables are seasonal, the Census x12 seasonal adjustment program is utilized for removing seasonal components. Within the modeling process, we allow the program to generate automatic settings for the lag orders of domestic $\left(p_{i}\right)$ and foreign $\left(q_{i}\right)$ variables through the Akaike Information Criterion, as well as the number of cointegration relationships between the variables $\left(r_{i}\right)$ selected using the appropriate Johansen test statistic. Therefore lag lengths and the number of relations described in Table 2. It is clear that the lag order of domestic and foreign variables in all provinces is one, and the 
number of cointegrating relations is lower than its maximum in all cases. Also, all individual unit models are estimated as case 4, restricted intercept, and no trend.

Table 2

Lag order and cointegrating relations for provincial models.

\begin{tabular}{lllll}
\hline Province & Dom Lag $\boldsymbol{p}_{\boldsymbol{i}}$ & For Lag $\boldsymbol{q}_{\boldsymbol{i}}$ & Case & Cointegration $\boldsymbol{r}_{\boldsymbol{i}}$ \\
\hline Azerbaijan East & 1 & 1 & 4 & 1 \\
Azerbaijan West & 1 & 1 & 4 & 1 \\
Ardabil & 1 & 1 & 4 & 1 \\
Isfahan & 1 & 1 & 4 & 2 \\
Ilam & 1 & 1 & 4 & 1 \\
Bushehr & 1 & 1 & 4 & 1 \\
Tehran & 1 & 1 & 4 & 1 \\
Chaharmahal & 1 & 1 & 4 & 1 \\
South Khorasan & 1 & 1 & 4 & 1 \\
Razavi Khorasan & 1 & 1 & 4 & 2 \\
North Khorasan & 1 & 1 & 4 & 2 \\
Khuzestan & 1 & 1 & 4 & 1 \\
Zanjan & 1 & 1 & 4 & 1 \\
Semnan & 1 & 1 & 4 & 1 \\
Sistan & 1 & 1 & 4 & 1 \\
Fars & 1 & 1 & 4 & 1 \\
Qazvin & 1 & 1 & 4 & 1 \\
Qom & 1 & 1 & 4 & 3 \\
Kurdistan & 1 & 1 & 4 & 1 \\
Kerman & 1 & 1 & 4 & 1 \\
Kermanshah & 1 & 1 & 4 & 1 \\
Kohgiluyeh & 1 & 1 & 4 & 1 \\
Golestan & 1 & 1 & 4 & 1 \\
Gilan & 1 & 1 & 4 & 1 \\
Lorestan & 1 & 1 & 4 & 1 \\
Mazandaran & 1 & 1 & 4 & 1 \\
Markazi & 1 & 1 & 4 & 1 \\
Hormozgan & 1 & 1 & 4 & 1 \\
Hamedan & 1 & 1 & 4 & 1 \\
Yazd & 1 & 1 & 4 & \\
\hline Note: The & 1 & 1 & \\
\hline
\end{tabular}

Note: The order of domestic lags, $p_{i}$, and foreign lags, $q_{i}$, are chosen by the AIC criterion. Numbers of cointegration relations $r_{i}$ are set by the Johansen Technique. Cases 2-4 refer to the type of restrictions on the deterministic components of the error correction model. They are restricted intercepts and no trend (Case 2), unrestricted intercepts and no trend (Case 3), and unrestricted intercepts and restricted trend (Case 4).

Source: Research Findings. 


\subsection{Contemporaneous Effects}

The contemporaneous effects of foreign variables on domestic ones are estimated by $\Lambda_{i 0}$ in (1). They measure to what extent variables $\mathrm{x}_{i t}=$ (une, inf, ind) in province i are affected by those of other provinces through either long term relationship (cointegration) or short-run (innovations) spillover effects. Table 3 summarizes the effects of foreign variables on a domestic counterpart. A precise high level of significance can be found in contemporaneous coefficients of inflation. Regarding unemployment, also, we can see the significance of contemporaneous coefficients for provinces such as Tehran, Semnan, Qom, Kurdistan, and Kermanshah. Approximately half of the contemporaneous coefficients of the ratio of manufactured valueadded to GDP are significant. These results confirming that there is indeed influence from other provinces on the observations in a province. The interpretation of figures is as follows: there is a $1 \%$ positive shock to unemployment in each of the 29 provinces. Then there will be a $0.57 \%$ increase in Tehran unemployment, and conversely, if there should be a $1 \%$ increase in the inflation of each of the 29 provinces, then Tehran will be increased $0.29 \% \mathrm{r}$. It is noteworthy to say that all significant contemporaneous coefficients are positive (except the manufactured coefficient of Kermanshah). 
Table 3

Contemporaneous effects of foreign variables on domestic counterparts

\begin{tabular}{|c|c|c|c|c|c|c|}
\hline \multirow[t]{2}{*}{ Province } & \multicolumn{2}{|c|}{ Unemployment } & \multicolumn{2}{|l|}{ Inflation } & \multicolumn{2}{|c|}{$\begin{array}{l}\text { GDP Share } \\
\text { Manufacturing }\end{array}$} \\
\hline & Coefficient & $\begin{array}{l}\text { Standard } \\
\text { error }\end{array}$ & Coefficient & $\begin{array}{l}\text { Standard } \\
\text { error }\end{array}$ & Coefficient & $\begin{array}{l}\text { Standard } \\
\text { error }\end{array}$ \\
\hline $\begin{array}{l}\text { Azerbaijan } \\
\text { East }\end{array}$ & -0.00497 & 0.388089 & $0.822676^{*}$ & 0.035342 & $0.984832 *$ & 0.290385 \\
\hline $\begin{array}{l}\text { Azerbaijan } \\
\text { West }\end{array}$ & 0.145241 & 0.268347 & $1.076822 *$ & 0.042227 & $0.713087 *$ & 0.247523 \\
\hline Ardabil & -0.09151 & 0.355161 & $1.177662 *$ & 0.056091 & $0.185834 *$ & 0.08714 \\
\hline Isfahan & 0.043718 & 0.349873 & $0.977715^{*}$ & 0.024299 & -0.13028 & 0.910906 \\
\hline Ilam & 0.476583 & 0.401877 & $0.95553 *$ & 0.028176 & 0.141006 & 0.133273 \\
\hline Bushehr & 0.278029 & 0.299119 & $0.951281 *$ & 0.061802 & 1.422577 & 1.146842 \\
\hline Tehran & $0.572545^{*}$ & 0.295471 & $0.957^{*}$ & 0.040262 & $0.819539 *$ & 0.397179 \\
\hline Chaharmahal & 0.038148 & 0.309067 & $1.006305^{*}$ & 0.024639 & -0.06826 & 0.20766 \\
\hline $\begin{array}{l}\text { South } \\
\text { Khorasan }\end{array}$ & 0.182883 & 0.379483 & $0.940303^{*}$ & 0.046172 & -0.38519 & 0.227118 \\
\hline $\begin{array}{l}\text { Razavi } \\
\text { Khorasan }\end{array}$ & 0.230833 & 0.258887 & $0.997692 *$ & 0.027126 & $0.783781 *$ & 0.222938 \\
\hline $\begin{array}{l}\text { North } \\
\text { Khorasan }\end{array}$ & -0.04174 & 0.264008 & $1.034104 *$ & 0.021709 & 0.111465 & 0.389035 \\
\hline Khuzestan & -0.15568 & 0.357795 & $0.88676^{*}$ & 0.026005 & -0.95256 & 0.511143 \\
\hline Zanjan & -0.33909 & 0.298391 & $1.052762 *$ & 0.02757 & -0.00291 & 0.355984 \\
\hline Semnan & $0.478584^{*}$ & 0.373261 & $1.003525^{*}$ & 0.037436 & 1.749668 & 0.948137 \\
\hline Sistan & -0.62733 & 0.39312 & $1.209933^{*}$ & 0.068332 & $0.517488 *$ & 0.098252 \\
\hline Fars & -0.15706 & 0.499606 & $1.094824^{*}$ & 0.040188 & $1.623435^{*}$ & 0.183573 \\
\hline Qazvin & -0.24535 & 0.281035 & $1.275674^{*}$ & 0.063825 & -0.28234 & 0.257988 \\
\hline Qom & $0.580445^{*}$ & 0.256188 & $0.967517^{*}$ & 0.018391 & $0.991926 *$ & 0.322935 \\
\hline Kurdistan & $0.940498 *$ & 0.376255 & $1.021045^{*}$ & 0.026643 & $0.863352 *$ & 0.201602 \\
\hline Kerman & 0.781504 & 0.674418 & $0.932788^{*}$ & 0.045147 & $1.440369^{*}$ & 0.641333 \\
\hline Kermanshah & $0.738416^{*}$ & 0.29929 & $0.978857^{*}$ & 0.025846 & $-0.96229 *$ & 0.462215 \\
\hline Kohgiluyeh & 0.116719 & 0.445832 & $0.859193^{*}$ & 0.026367 & $0.182121 *$ & 0.032061 \\
\hline Golestan & 0.520832 & 0.35766 & $0.959928^{*}$ & 0.054538 & -0.216 & 0.13263 \\
\hline Gilan & 0.45763 & 0.39316 & $0.943278^{*}$ & 0.038284 & $0.282511 *$ & 0.105443 \\
\hline Lorestan & -0.0663 & 0.438326 & $1.123482 *$ & 0.019623 & 0.12471 & 0.281299 \\
\hline Mazandaran & -0.05575 & 0.346864 & $0.952513^{*}$ & 0.031808 & $0.59141 *$ & 0.160439 \\
\hline Markazi & 0.352283 & 0.366147 & $0.977308^{*}$ & 0.03516 & 0.418423 & 0.40491 \\
\hline Hormozgan & 0.047087 & 0.304581 & $0.943738^{*}$ & 0.043603 & $1.829738^{*}$ & 0.231264 \\
\hline Hamedan & 0.531175 & 0.384556 & $1.213232 *$ & 0.024681 & -0.16267 & 0.219829 \\
\hline Yazd & -0.25829 & 0.293472 & $1.10077 *$ & 0.060515 & $0.865781 *$ & 0.290385 \\
\hline
\end{tabular}

* Significance at the 5\% Level

Source: Research Findings.

\subsection{Dynamic Analysis}

Interpretation of the practical implications of the model for policymakers takes into account shock impacts. The spillovers and effects identified in the previous section ensure that shocks in one province may have different implications in other provinces and variables, as exemplified by our GIRF analysis. 


\subsubsection{Generalized Impulse Response Functions (GIRFs)}

The exploration of the dynamic properties of the GVAR model is carried out using the generalized impulse response functions (GIRFs) developed by Pesaran and Shin (1998) for vector error correction models embedded here. We consider provincial responses to positive national monetary shock.

Plots in Fig. 1 show that the response of unemployment in 5 provinces (including Isfahan, Kerman, Razavi Khorasan, Markazi, and Lorestan) is negative and statically significant. Based on our results, we can say that in some provinces such as Isfahan, Kerman, and Markazi, which share of the manufacturing of GDP is considerable; unemployment could trigger response significantly. It is worth noting that this conclusion is not absolute. For example, unemployment in some provinces like Semnan, with about 29\% manufacturing share of GDP, has not responded to monetary shock. Also, in some provinces such as Bushehr and Khuzestan, unemployment does not reflect significant response because of the important role of the gas and oil sector (capital intensive sector) in their provincial GDP. Besides, in provinces that have a major share of the value-added services sector of GDP, the response of unemployment is not significant. This conclusion, of course, has exceptions, such as Razavi Khorasan.

The remarkable matter about significant responses of unemployment is that all of them have a similar shape approximately in the framework of time. Despite similar timing and form in response to the national monetary shock, the intensity of responses is different. 


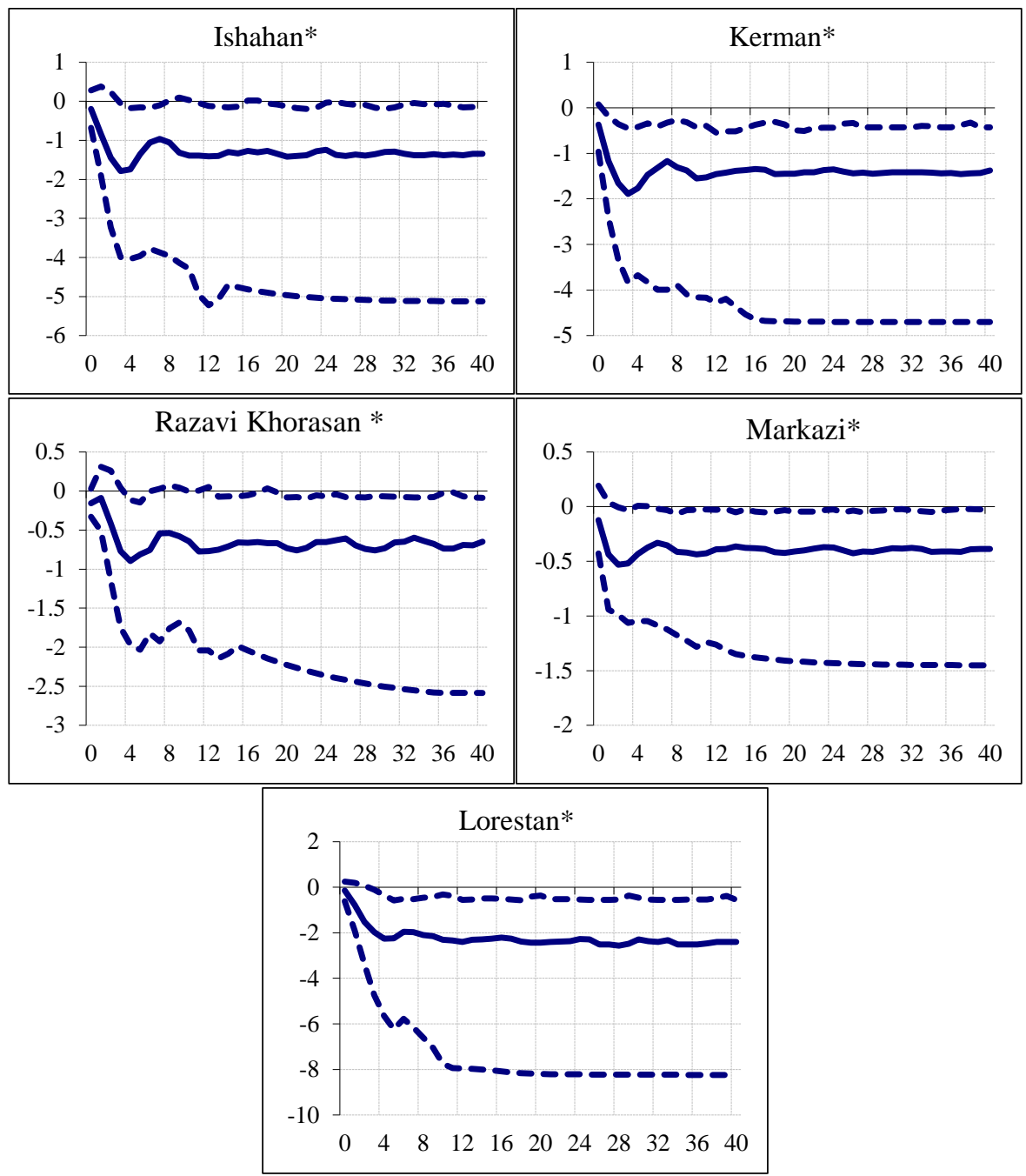

Figure 1. Provincial Unemployment Responses to National Monetary Shocks, Note: Responses indicated to one standard deviation positive national monetary shock on provincial unemployment. In all plots, solid lines indicated the response of unemployment and dashed lines denote the confidence interval (or bound). If the confidence interval does not contain zero (horizontal axis), then the response is statically significant.

* Significance at the 5\% Level, Source: Research Findings. 
Inflation responses to positive monetary shocks with a similar form and time framework in all provinces. However, the intensity of the reactions varies. Fig. 2 shows the response of inflation in some provinces.

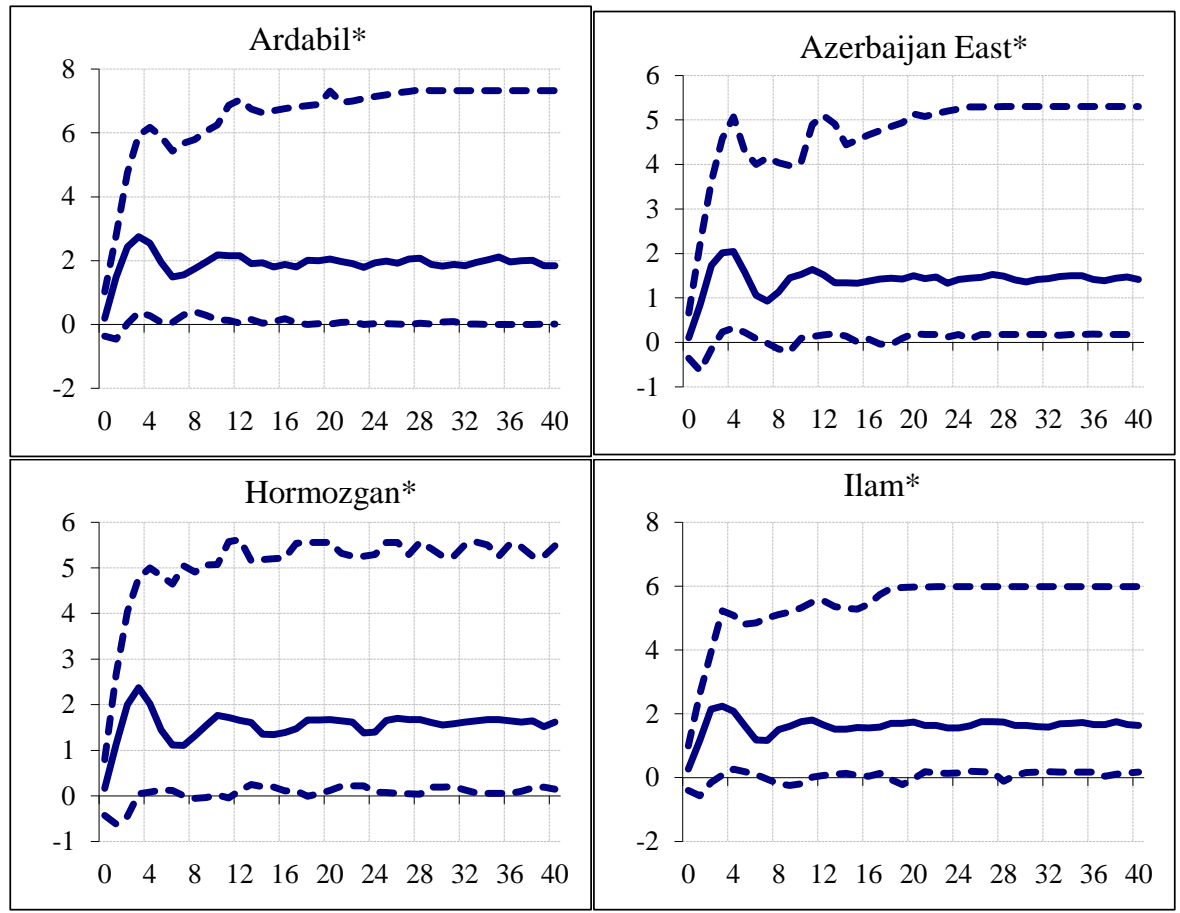

Figure 2. Provincial Inflation Responses to National Monetary Shocks, Note: Responses indicated to one standard deviation positive national monetary shock on provincial inflation. In all plots, solid lines indicated the response of inflation and dashed lines denote the confidence interval (or bound). If the confidence interval does not contain zero (horizontal axis), then the response is statically significant.

* Significance at the 5\% Level

Source: Research Findings.

\subsubsection{Generalized Forecast Error Variance Decompositions (GFEVDs)}

The forecast error variance decomposition is closely related to the impulse response analysis, which shows the relative contributions of the shocks to reducing the mean square error of forecasts of individual endogenous variables at a given time horizon. The GFEVDs are based on GIRFs. 
As it was denoted, the central bank of Iran applies monetary policy uniformly for all provinces. So, when we want to present the contribution of the $\mathrm{N}$-step ahead forecast error variance of a given province M2, it is clear that M2 has the most contribution among variables of each province. Therefore, to decompose the forecast error variance M2 of a given province, which its unemployment significantly responded, we present the proportion of its domestic variables. Notice that due to the non-zero correlation between errors, individual contributions to GFEVD don't need sum unity. To avoid of prolongation, we show only GFEVD results for Isfahan in table 4. Corresponding to these results, M2 has the most contribution in reducing the mean square error of forecasts among all domestic variables. This share has decreased over time. However, the share of unemployment and inflation in cutting the mean squares of the forecast error has increased over time. It should be noted that these shares vary in size over time horizons.

Table 4

GFEVD of Isfahan

\begin{tabular}{|c|c|c|c|c|c|c|c|c|c|c|c|}
\hline \multicolumn{12}{|c|}{ The proportion of the N-step ahead Forecast Error Variance of Isfahan } \\
\hline Quarter & 0 & 4 & 8 & 12 & 16 & 20 & 24 & 28 & 32 & 36 & 40 \\
\hline M2 & 0.60 & 0.32 & 0.32 & 0.31 & 0.31 & 0.31 & 0.31 & 0.31 & 0.30 & 0.30 & 0.30 \\
\hline unemployment & 0.01 & 0.11 & 0.11 & 0.11 & 0.12 & 0.12 & 0.13 & 0.13 & 0.13 & 0.13 & 0.13 \\
\hline Inflation & 0.01 & 0.16 & 0.19 & 0.19 & 0.20 & 0.20 & 0.20 & 0.21 & 0.21 & 0.21 & 0.21 \\
\hline $\begin{array}{l}\text { GDP share of } \\
\text { Manufacturing }\end{array}$ & 0.02 & 0.06 & 0.06 & 0.06 & 0.05 & 0.05 & 0.05 & 0.05 & 0.05 & 0.05 & 0.05 \\
\hline
\end{tabular}

Source: Research Findings.

\section{Conclusion and Policy Implication}

Monetary policy is a combination of rules and measures to achieve objectives such as relative price stability. That is implemented at the national level by the central bank. Monetary policy, in addition to has short-run or medium run effects at the national and macro level, also affects different regions (provinces) of a country. This impact can be due to differences in the combination of industries, firms, and banks in different regions. Therefore, evaluating the response of these regions can be useful in regional planning as a roadmap for planners and policymakers. Since Iran is comprised of provinces that have different economic and non-economic characteristics, one might expect different responses to monetary policy. In this regard, in this paper, the effects of monetary policy in Iranian provinces were investigated using GVAR approach. 
Based on the results of the provinces' response to the positive monetary shock in the framework of the model designed in this study, it was found that the unemployment response of some provinces was statistically significant, and the response of others was not significant. It was also found that the significant unemployment responses of the different provinces were similar in terms of timing and form but different in intensity. Significant unemployment responses across the provinces were also negative. Also, the inflation response in all provinces was statistically significant. Inflation in all provinces reacted with similar behavior in terms of timing. Despite this similarity, responses vary in terms of intensity. Significant inflation responses in all provinces have been positive. Regarding the results of the decomposition of variance of the monetary shock forecast error, it was found that the share of unemployment and inflation in the mean square error reduction was different in the provinces and time horizons.

Given these results, it can be said that monetary policy in the provinces with a significant share of the manufacturing sector can create new job opportunities and move their economic structure towards industrialization. However, the high share of value-added and employment in the economy of most provinces of the country belongs to the service sector. Therefore, adopting an expansionary monetary policy will not have a significant impact on provincial unemployment. But it only has an inflationary effect in all provinces. Therefore, policymakers should consider both the provincial differences and the inflationary consequences of their liquidity injection into the economy. Using qualitative monetary policy tools with a regional (provincial) view, such as setting regional priorities in the use of credit, can help to balance regional policy development in addition to controlling monetary policy effects.

\section{References}

Arnold, I. J., \& Vrugt, E. B. (2002). Regional Effects of Monetary Policy in the Netherlands. International Journal of Business and Economics, 1(2), 123

Arnold, I. J., \& Vrugt, E. B. (2004). Firm Size, Industry Mix, and the Regional Transmission of Monetary Policy in Germany. German Economic Review, 5(1), 35-59.

Beckworth, D. (2015). The Regional Effects of Monetary Policy: The Case of the American South. Essays in Economic \& Business History, 34(1), 22-59.

Carlino, G. A., \& DeFina, R. (1998). Monetary Policy and the U.S. And Regions: Some Implications for European Monetary Union. Working Papers 98-17, Federal Reserve Bank of Philadelphia. 
Money and Economy, Vol. 15, No. 1, Winter 2020

Carlino, G. A., \& DeFina, R. (1999). The Differential Regional Effects of Monetary Policy: Evidence from the U.S. States. Journal of Regional Science, 39(2), 339358.

Chudik, A., \& Pesaran, M. H. (2016). Theory and Practice of GVAR Modelling. Journal of Economic Surveys, 30(1), 165-197.

Di Giacinto, V. (2003). Differential Regional Effects of Monetary Policy: A Geographical Evidence from the U.S. States. Journal of Regional Science, 39(2), 339-358.

Ehrmann, M. (2005). Firm Size and Monetary Policy Transmission-Evidence from German Business Survey Data. In IFO Survey Data in Business Cycle and Monetary Policy Analysis (pp. 145-172). Physica-Verlag HD.

Foroughifar, M. (2016). The Dynamic Effects of Monetary Policy on Provincial Unemployment in Iran. MA Thesis, University of Tehran.

Georgiadis, G. (2014). Towards an Explanation of Cross-Country Asymmetries in Monetary Transmission. Journal of Macroeconomics, 39, 66-84.

Guo, X., \& Masron, T. A. (2017). Regional Effects of Monetary Policy in China: Evidence from China's Provinces. Bulletin of Economic Research, 69(2), 178208.

Ireland, P (2006). The Monetary Transmission Mechanism, Working Papers 06-1, Federal Reserve Bank of Boston.

Kashyap, A. K., \& Stein, J. C. (1995). The Impact of Monetary Policy on Bank Balance Sheets. In Carnegie-Rochester Conference Series on Public Policy (Vol. 42, pp. 151-195). North-Holland.

Mishkin, F. S. (1995). Symposium on the Monetary Transmission Mechanism. Journal of Economic Perspectives, 9(4), 3-10.

Mishra, P., Montiel, P., \& Sengupta, R. (2016). Monetary transmission in developing countries: Evidence from India. In Monetary Policy in India (pp. 59-110). Springer, New Delhi.

Nachane, D. M., Ray, P., \& Ghosh, S. (2002). Does Monetary Policy Have Differential State-Level Effects? An Empirical Evaluation. Economic and Political Weekly, 4723-4728.

Owyang, M. T., \& Wall, H. J. (2009). Regional VARs and the Channels of Monetary Policy. Applied Economics Letters, 16(12), 1191-1194.

Pesaran, M. H., \& Shin, Y. (1998). An Autoregressive Distributed-Lag Modelling Approach to Cointegration Analysis. Econometric Society Monographs, 31, 371413.

Raabe, K., Arnold, I., \& Kool, C. J. (2006). Firm Size and Monetary Policy Transmission: A Theoretical Model on the Role of Capital Investment Expenditures. Discussion Paper Series/Tjalling C. Koopmans Research Institute, 6(14).

Ridhwan, M. M., de Groot, H. L., Nijkamp, P., \& Rietveld, P. (2010). The Impact of Monetary Policy on Economic Activity-Evidence from a Meta-Analysis. 
Ridhwan, M. M., Groot, H. L., Rietveld, P., \& Nijkamp, P. (2014). The Regional Impact of Monetary Policy in Indonesia. Growth and Change, 45(2), 240-262.

Romer, Christina D., \& Romer, David H. (1990). New Evidence on the Monetary Transmission Mechanism. Brookins Parers on Economic Activity, 149-213.

Silva, I. É. M. (2016). The Differential Regional Effects of Monetary and Fiscal Policies in Brazil. In Anais do XLII Encontro Nacional de Economia [Proceedings of the 42ndd Brazilian Economics Meeting] (No. 040). ANPECAssociação Nacional dos Centros de Pósgraduação em Economia [Brazilian Association of Graduate Programs in Economics]. SVAR approach. International Regional Science Review 26(3), 313-341.

Taylor, J. B. (1995). The Monetary Transmission Mechanism: An Empirical Framework. Journal of Economic Perspectives, 9(4), 11-26.

Xiaohui, G., \& Masron, T. A. (2014). Regional Effects of Monetary Policy in China: The Role of Spillover Effects. Asian Academy of Management Journal, 19(1). 


\section{Appendix}

\section{Migration Weight Matrix}

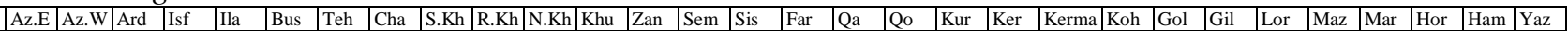

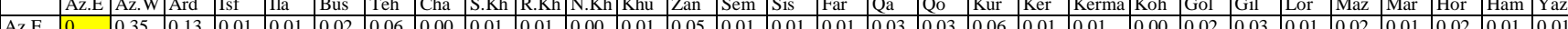

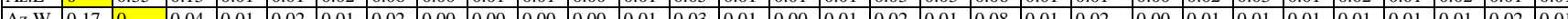

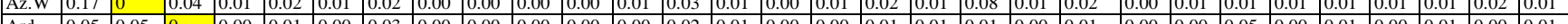

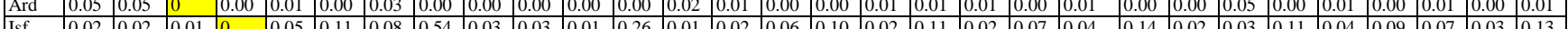

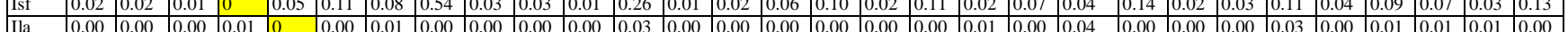

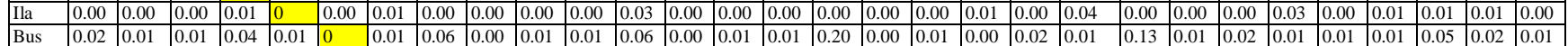

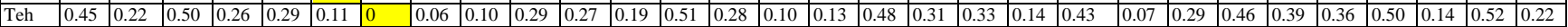
\begin{tabular}{lllllllllllllllllllllllllllllllllllllllll} 
Cha & 0.00 & 0.00 & 0.00 & 0.07 & 0.01 & 0.01 & 0.00 & 0 & 0.00 & 0.00 & 0.00 & 0.03 & 0.00 & 0.00 & 0.00 & 0.01 & 0.00 & 0.01 & 0.00 & 0.00 & 0.00 & 0.02 & 0.00 & 0.00 & 0.00 & 0.00 & 0.00 & 0.01 & 0.00 & 0.01 \\
\hline
\end{tabular}

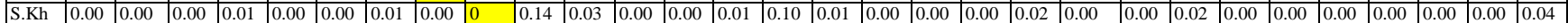

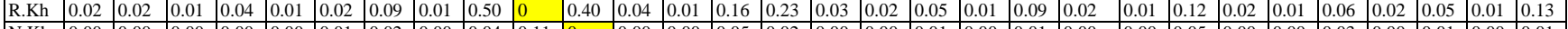

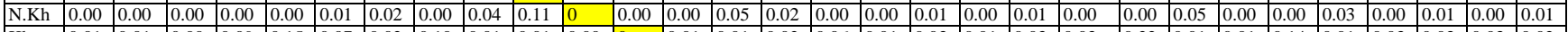

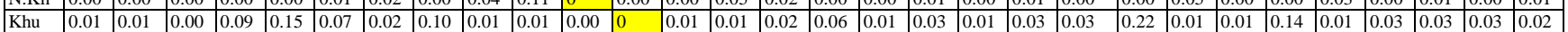

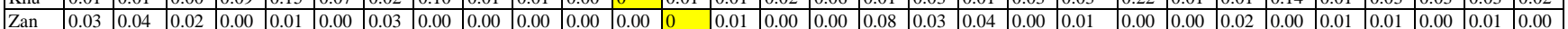

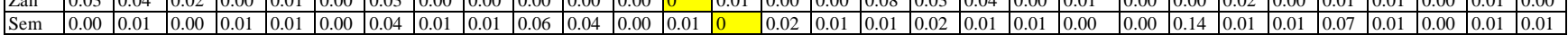

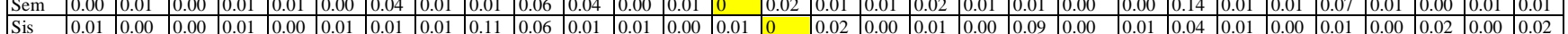

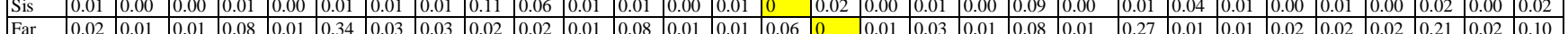

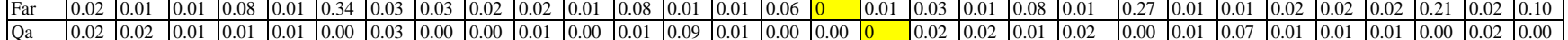

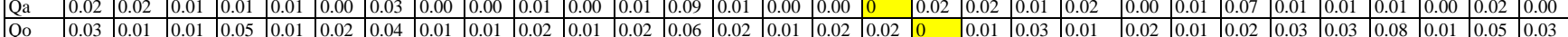

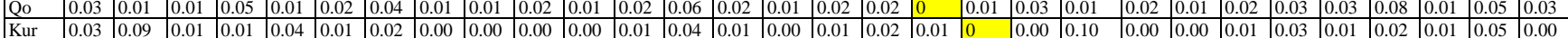

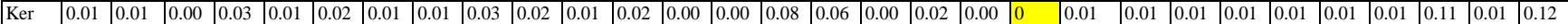

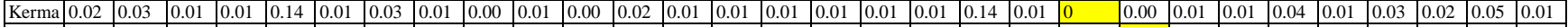

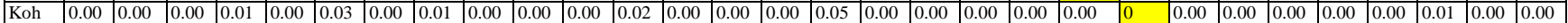

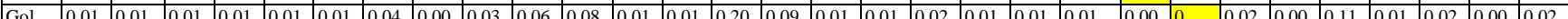

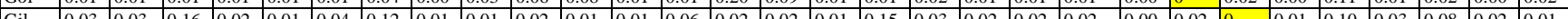

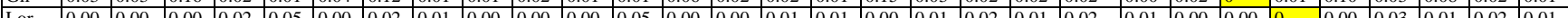

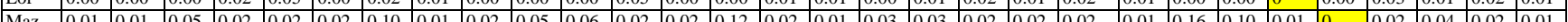

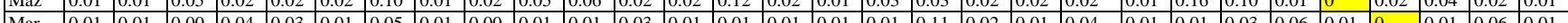

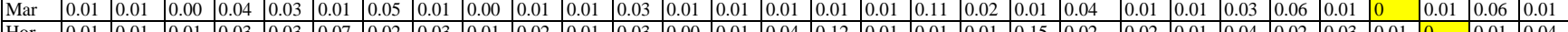

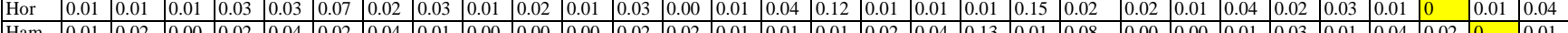

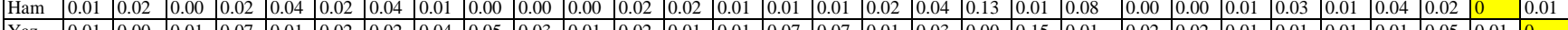

